\title{
Endophytic Fungi in Bamboo: A Review
}

\author{
Jentu Giba, Tonlong Wangpan and Sumpam Tangjang* \\ Department of Botany, Rajiv Gandhi University, Rono Hills, Doimukh, \\ Arunachal Pradesh, India \\ *Corresponding author
}

\section{A B S T R A C T}

\section{Keywords \\ Endophytes, bamboo, Arunachal Pradesh, bambusicolous fungi \\ Article Info \\ Accepted: 15 October 2020 Available Online: 10 November 2020}

The Plants are reservoir of large numbers of microorganisms known as endophytes that resides inside the plants with inconspicuous symptoms. The association of grasses with microorganisms, including fungal endophytes, is abundant and is vital to maintain the grasses' ecological health and the species diversity. The Bamboo is an essential plant, intertwining with native people indicates the opportunity to find new strains of endophytic fungi and as potential sources of novel natural products. Arunachal Pradesh, one of the world's biodiversity hotspots with $80 \%$ of the total state area under forest cover, will provide a vast potential for the research on endophytic fungi.

\section{Introduction}

Since the emergence of the term "symbiosis", which has been described as the living together of different organisms by De Bary in 1879, an array of symbiotic lifestyles has been defined based on benefits and impacts to macroscopic hosts microscopic symbionts (Lewis, 1985). Plants are a reservoir of large numbers of microorganisms known as endophytes (Bacon and White, 2000). De Bary (1866) originally introduced the word "endophyte", with 'endo' meaning inside and 'phyte' meaning plants. So, endophyte refers to the organisms that live within the plants (Wilson, 1995).
There have been diverse ways of defining the word 'endophytes'. Still, the most accepted definition was given by Stone et al., (2000), which defines endophytes as those organisms whose "infections are inconspicuous, the infected host tissues are at least transiently symptomless, and the microbial colonization can be demonstrated to be internal". The researchers used this definition to describe the fungal endophytes. The same definition, however, is equally valid for the bacterial endophytes (Stone et al., 2000).

The fossil record supported the plants' symbiotic relationships with the endophytic or the mycorrhizal fungi for about 400 million 
years. It was likely to be associated when plants colonized the land, thus playing a crucial role in driving the evolution of life on earth (Krings et al., 2007; Redecker et al., 2000). The endophytes are very diverse and are termed as ubiquitous (Stone et al., 2000; Petrini, 1991). They are also known to produce various functional metabolites (Tan and Zou, 2001). Their relationship with its host ranges from the latent phytopathogenic to a mutualism (Saikkonen et al., 1998; Azevedo et al., 2000).

More than a hundred years of research suggests that most plants in natural ecosystems have a symbiotic relationship with the endophytes (Petrini, 1986). They infect the tissue of the healthy plants for all or nearly all their lives without any symptoms for years and become parasitic only when their host is stressed (Firakova et al., 2007; Limsuwan et al., 2009).

\section{Bamboo and their endophytes}

Documentation of the endophyte and its association with the bamboo as a host has been undermined. Very negligible research has been reported to study the relationship between the endophytic fungi and the bamboo species. The bamboo, belonging to the family of grass, Poaceae, lacks the biosynthetic capacity to synthesize the secondary metabolites compared to the dicotyledonous plants, which are useful in the long-term survival strategy of each species. This lack of secondary metabolites' production, however, is accounted by notorious microorganisms living in a cohabitate condition with the grasses.

This association of grasses with microorganisms, including fungal endophytes, is abundant and is vital to maintain the grasses' ecological fitness and the species diversity (Kuldau et al., 2008).
More than 1100 species of bambusicolous fungi are recorded, including the endophytic fungi with very limited known from bamboo seeds (Mohanan, 1997; Hyde et al., 2002; Shukla et al., 1998; Cai et al., 2003). The infection of grasses by the endophytic fungi has been recorded over a century now (Freeman, 1904; Schardl et al., 2004); still, its hyphal morphology and the growth concerning the cells of the host continue to evolve the questions on the mechanism of colonization (Tan et al., 2001). The fungal growth paradigm prevails to explain that the vegetative hyphae grow exclusively by division and increased hyphal compartments at the apex (Bartnicki-Garcia, 2002; Harold, 2002). Until recently, the transmission of endophytic fungi in bamboo is described to be non-systemic and horizontally transmitted. Even then, systemic and the vertically transmitted endophytes cannot be ruled out in bamboos because they are commonly found in other grasses (Saikkonen et al., 2004, 2007).

Compared to the other perennial grasses, the fast growth, age of the sexual maturity, and semelparity of the bamboo offer a significantly minimized systemic growth opportunities for the endophytic fungi (Saikkonen et al., 2004). The statement was further supported by Helander et al., (2013), stating that the endophytes are found only in the local horizontal transmission colonizing their bamboo samples.

\section{Diversity of endophytic fungi in bamboo}

The diverse range of the bamboo species in an ecosystem ranging from the temperate evergreen valleys to the high mountains presumably vary in its endophytic colonization, which is primarily defined by the host plant's altitude and environment. The current statement was supported by Doungporn et al., (2006), where different 
fungi species were isolated from a separate area of collection of the host plant, suggesting that the diversity of the endophytic fungi are influenced by the habitat, the region, and the range of their hosts. So, it would be interesting to investigate the ecological community.

Hyde et al., (2002) recorded about 500 species of bamboo endophyte in Asia, of which $38 \%$ were recorded only from Japan. All the data related to the fungi associated with the bamboo have been recorded by Hino and Katumoto (1961). Doungporn et al., (2006) isolated some more endophytic fungi that were not recorded by Hino and Katumoto in 1961. A list of new fungi species isolated were Peziza, Diaporthe, Sordaria, Alternaria, and Microdochium. Much of the research work had been done on the calvicipitalean endophytes (Clay, 1990), and a new genus Heteroepichloe was included by Tanaka et al., (2002).

White (1997) included the seed transmitted endophytic fungi such as Neotyphodium lolii, $N$. coenophialum, and Epichloe festucae that were biotrophs and displayed stable symbiosis with the grass family (Schardl et al., 2004; Schardl and Phillips, 1997). Further, Clay and Holah (1999) described their presence in host meristems throughout the leaves and the reproductive structures, evidently enhancing their hosts' survival.

The endophytic fungi associated with bamboo mostly belong to the phylum Ascomycotina and are primarily categorized under the class Dothideomycetes and Sordariomycetes. Both Morakotkarn et al., (2007) and Shen et al., (2012) supported that most of the endophytic fungi from the tissues of bamboos have been identified from the class Dothideomycetes and Sordariomycetes. Similar findings were reported by Shen et al., (2014), while attempting to isolate the endophytic fungi from the Moso bamboo seeds based on their ITS region. They were able to isolate 350 fungal isolates distributed in 69 morphotypes based on the cultural characteristics and obtained at least ten genera from Dothideomycetes, seven genera under Sordariomycetes, and two and one genera in Agaricomycetes and Eurotiomycetes, respectively. Further, the sequence alignment depicted that the isolates belonged to the phylum Ascomycota (343 isolates) and Basidiomycota ( 7 isolates) with colonization frequency of $98.0 \%$ and $2.0 \%$, respectively. In their study, they also reported some genera like Cladosporium, Phoma, and Curvularia as endophytes for the first time, which have previously been considered as pathogens for some bamboo species and its seeds, excluding Moso bamboo (Mohanan, 1997). Other genus including Leptosphaerulina (1.71\%), Simplicillium (0.57\%), Sebacina (1.71\%), and an undetermined genus (2.86) were also a new addition as bambusicolous fungi, which were previously considered as the pathogens (Chen et al., 2008; Kharkwal et al., 2007; Thal et al., 1986).

Recent studies have unveiled several new species of Endophytes in Bamboo. Arzanlou and Khodaei (2012) identified a new bamboo endophyte, Aureobasidium iranianum (Deuteromycetes), associated with the healthy bamboo stem. Khan and Uniyal (1999) isolated and recorded Ambispora, a dark septate fungus, for the first time from the bamboo species, the Dark septate endophytes (DSE) mainly comprise of a variety of rootinhabiting group of fungi. The DSE as sterile fungi belonging to the phylum Ascomycota colonize the living plant roots without causing any apparent adverse effects (Jumpponen and Trappe, 1998). Recently, Parkash and his coworker in 2019 investigated on diversity and distribution of endomychorriza and the DSE on bamboo species, Bambusa bamboos, $B$. tulda, B. pallida and B. nutans of Assam, 
India. They have observed $100 \%$ colonization of ectomycorrhiza and infection of hyphal DSE in the roots of all the bamboo species.

\section{Significance of the bamboo endophytes}

Most of the study related to the bamboo endophytes have been focused on a variety of aspects such as increasing the silica content for the growth of panda (Helander, 2013), enumerating the diversity of the DSE (Parkash et al., 2019; Das and Kayang, 2010), focusing on a particular tissues of a particular bamboo species (Shen et al., 2014), Witche's symptoms on bamboo due to endophytic fungi (Tanaka, 2009) and the more general association of the endophytic fungi with grass family.

The importance of the endophytic fungi associated with the bamboo as a source of novel bioactive products in the agriculture and the food industry has already been proven and established (Verma et al., 2009; Gunatilaka, 2006; Strobel et al., 2004). Shen et al., (2014) demonstrated 69 representative endophytes' antimicrobial activities from Moso bamboo seeds against the clinical pathogens. They selected the bacteria and the yeast as model microorganisms for antimicrobial analysis and found that the endophytic strain Cladosporium spp. Depicted the inhibitory action against the growth of the two human pathogenic bacteria, Straphylococcus aureus and Bacillus subtilis, whereas Pencillium spp. displayed the most comprehensive spectrum of antimicroorganism against $S$. aureus, B. subtilis, Listeria monocytogenes, Salmonella spp., Candida albicans and Rhodotorula rubra.

The endophytic fungi of the bamboo have also been found to be an essential component for the production of hormones in their plant host. For instance, the endophytic fungi found in the meristematic tissues were responsible for the continuous primordium initiation in the shoot apex via auxin production (Tanaka et al., 2003, 2009). The colonized shoot may not have the ability to produce a sufficient quantity of the endogenous free IAA for the leaves and stem expansion, which can be tackled by Aciculosporium take hyphae found within the apical meristem, which may be producing the exogenous free IAA for inducing primordium initiation and maintaining the apical dominance.

Based on the histological study, they postulated that A. take stroma formation destroys the shoot apical meristem. As a result, the endophytic hyphae pass through the epidermis to form stroma. Christensen et al., (2008) postulated a novel growth mechanism via infection in the grasses by the vegetative hyphae of Neotyphodium and Epichloe species, followed by the intercalary division and expansion. The attached hyphae to the enlarging host cells and the collective growth along the filaments' length help the fungi extend at the same rate as their host. The mentioned study was the first evidence of the intercalary growth in the fungi, which challenges the century-old model describing the fungal growth in exclusive hyphal tips.

The endophytic fungi associated with the bamboo also enhance the contiguous composition and increasing the crude protein content of corn cob, hence giving an alternative to expensive animal feeds (Paynor, 2016). Besides being potent and versatile in its production for secondary metabolite, the endophytic fungi isolated from the bamboo also encourage input in bambusicolous fungi' diversity. As the previous studies have mentioned, the bambusicolous fungi also display some significant medicinal effects similar to their host or are even more useful. Ingredients like Cytochalasin- $\mathrm{C}$ and neoengleromycin from Engleromyces sinensis (Ma et al., 2004) and hypocrellins from 
Hypocrella bambusae and Shiraia bambusicola, are active ingredients from the medicinal macrofungi related with the bamboo species and displaying broadspectrum activity against clinical microorganism and virus (Liu et al., 2002; Zhan et al., 2003; Ma et al., 2004; Ali et al., 2002; Wan et al., 1981).

Shen et al., (2014) unravelled macrofungi named Shiraia bambusicola as endophytic fungi from Moso bamboo seeds. Their strain coded zzz816 was closely related with $S$. bambusicola in ITS sequence analysis. $S$. bambusicola is mainly found in Brachystachyum densiflorum and its related species in China and Bambusa species in Japan (Li et al., 2009; Hino, 1961). This fungal fruiting body has been used in traditional medicine in China and found it's compound to have antitumor and antiangiogenetic properties ( $\mathrm{Li}$ et al., 2009). Its principle ompound, hypocrellins, has attracted a great deal of attention because of its light-induced antifungal, antitumor, and antiviral activities (Cai et al., 2011; Yang et al., 2009). Shen and co-workers in 2014, while working on Moso bamboo seeds, isolated $S$. bambusicola. Their preliminary test for antimicrobial activity found that $S$. bambusicola exhibited the highest content of hypocrellins among all other isolates. There is a possibility of improving the compound by breeding novel industrial mutants and optimizing the fermentation process.

In conclusion research on endophytic fungi and its association with the bamboo species has been minimal. Until recently, their investigation had been taken into consideration in only some parts of Asia. There has been negligible literature recorded so far in the Eastern Himalaya, especially from Arunachal Pradesh. The bamboo plays a central role in the lifestyle among the rural folk of the state, from construction to medicine to their local cuisine, and mostly in the wild condition. Arunachal Pradesh, one of the world's biodiversity hotspots with about $80 \%$ of the state's total area under forest cover, will provide a vast potential for the documentation of the endophytic fungi based on the region of the collection of the host plant. The bamboo is an essential plant, intertwining with indigenous folk, indicating the opportunity to find new strains of endophytic fungi and as potential sources of novel natural products. The detailed understanding of the diversity of endophytes on bamboo species will help to chart and document the primary data, fill the gap, and establish future research. Furthermore, the microorganisms may be screened for a wide range of biological activities and explored for useful chemical entities produced continuously by them, including antimicrobial and extracellular enzymatic activities. Thus, an extensive study on endophytic fungal diversity from diverse bamboo species and also the in-depth research on their secondary metabolites is crucial.

\section{Acknowledgment}

The authors are thankful to University Grant Commission (UGC), New Delhi, for providing the fellowship for carrying out the present investigation.

\section{References}

Ali, S.M., and Olivo, M. 2002. Efficacy of hypocrellin pharmacokinetics in phototherapy. International Journal of Oncology 21: 1229-1237.

Arzanlou, M., and Khodaei, S. 2012. Aureobasidium iranianum, a new species on bamboo from Iran. Mycosphere 3(4): 404-408, Doi 10.5943 /mycosphere/3/4/2.

Bacon, C.W., and White, J.F. 2000. Microbial Endophytes. Marcel Deker, New York, 
USA.

Bartnicki, G.S. 2002. Hyphal tip growth: Outstanding questions. In: Osiewacz, H.D. (Ed.), Molecular Biology of Fungal Development. Marcel Dekker, New York, pp. 29-58.

Cai, L., Zhang, K.Q., McKenzie, E.H.C., and Hyde, K.D. 2003. Freshwater fungi from bamboo and wood submerged in the Liput River in the Philippines. Fungal Diversity 13: 1-12.

Cai, Y., Liao, X., Liang X., Ding, Y., and Sun, J. 2011. Induction of hypocrellin production by Triton X-100 under submerged fermentation with Shiraia sp. SUPER-H168. Nature Biotechnology 28: 588-592.

Chen, R.S., Huang, C.C., Li, J.C., and Tsay, J.G. 2008. First report of Simplicillium lanosoniveum causing brown spot on Salvinia auriculata and S. molesta in Taiwan. Plant Disease 92: 1589-1589.

Christensen, M.J., Bennett, R.J., Ansari, H.A., Koga, H., Johnson, R.D., and Bryan, G.T. 2008. Epichloë endophytes grow by intercalary hyphal extension in elongating grass leaves. Fungal Genetics and Biology 45: 84-93.

Clay, K. 1990. Fungal endophytes of grasses. Annual review of ecology and systematics 21: 275-297.

Clay, K., and Holah, J. 1999. Fungal Endophyte Symbiosis and Plant Diversity in Successional Fields. Science 285 (5434): 1742-5. DOI: 10.1126/science.285.5434.1742.

De Bary, A. 1879. Die Erscheinung der Symbiose. In: Trubner KJ, ed. Vortrag auf der Versammlung der Naturforscher und Ärtze zu Cassel. Strassburg, Germany; Verlag, 1-30.

De Bary, A. 1866. Morphologie und Physiologie Pilze, Flechten, und myxomyceten. Hofmeister's Handbook of Physiological Botany. Vol. 2. Leipzig. Doungporn, M., Hiro, K. and Tatsuji S. 2006.
Molecular diversity of bamboo associated fungi isolated from Japan. The international center of biotechnology,Osaka University, Osaka, Japan.

Firakova, S., Sturdikova, M., and Muckova, M. 2007. Bioactive secondary metabolites produced by microorganisms associated with plants. Biologia. 62(3): 251-257.

Freeman, E.M. 1904. The seed fungus of Lolium temulentum L., the darnel. Philos. Trans. R. Soc. Lond. B 214: 128.

Kuldau, G., and Bacon, C. 2008. Clavicipitaceous endophytes: Their ability to enhance resistance of grasses to multiple stresses. Biological Control 46: 57-71.

Gunatilaka, A.A.L., 2006. Natural products from plant-associated microorganisms: distribution, structural diversity, bioactivity, and implications of their occurrence. Journal of Natural Products 69: 505-526.

Harold, F.M. 2002. Force and compliance: rethinking morphogenesis in walled cells. Fungal Genetics and Biology 37: 271-282.

Helander, M., Jia, R., Huitu, O., Sieber, T.N., Jia, J., Niemelä, P., and Saikkonen, K. 2013. Endophytic fungi and silica content of different bamboo species in giant panda diet. Symbiosis 61: 13-22. DOI 10.100 7/S13199-013-0253-2.

Hino, I. 1961. Icones fungorum Bambusicolorum japonicorum. The Fuji Bamboo Garden, Gotenba, Japan.

Hino, I. and Katumoto, K. 1961. Illustrationes fungorum bambusicolorum IX. Bulletin of the Faculty of Agriculture, Yamaguti University 12: 151-162.

Hyde, K.D., Zhou, D.Q., and Dalisay, T. 2002. Bambusicolous fungi: A review. Fungal Diversity 9: 1-14.

Jumpponen, A. and Trappe, J.M. 1998. Dark 
septate endophytes: a review of facultative biotrophic root colonizing fungi. The New Phytologist 140(2): 295-310.

Khan, S.N. and Uniyal, K. 1999. Association of arbuscular mycorrhizal fungi with different bamboo species at a reforested site. Ind J For 22: 405-408.

Kharkwal, A.C., Prasad, R., Kharkwal, H., Das A. and Bhatnagar K. 2007. Cocultivation with sebacinales. Soil Biology 11: 247-270.

Krings M., Taylor T.N., Hass H., Kerp, H., Dotzler, N., and Hermsen, E.J. 2007. Fungal endophytes in a 400-million-yrold land plant: infection pathways, spatial distribution, and host responses. New Phytologist 174: 648-657.

Lewis, D.H. 1985. Symbiosis and mutualism: crisp concepts and soggy semantics. In: Boucher DH, ed. The biology of mutualism. London, UK: Croom Helm Ltd, 29-39.

Li, X.M., Gao, J., Yue, Y.D., and Hou, C.L. 2009. Studies on systematics, biology and bioactive substance of Shiraia bambusicola. Forest Research 22: 279284.

Liu, J.K., Tan, J.W., Dong, Z.J., Ding, Z.H., and Wang, X.H. 2002. Neoengleromycin, a novel compound from Engleromyces goetzii. Helvetica Chimica Acta 85: 1439-1442.

Ma, G., Khan, S.I., Jacob, M.R., Tekwani, B.L., and Li, Z. 2004. Antimicrobial and antileishmanial activities of hypocrellins $A$ and B. Antimicrobial Agents and Chemotherapy 48: 4450-4452.

Mohanan, C. 1997. Diseases of bamboos in Asia: an illustrated manual. Beijing, Eindhoven and New Delhi: International Development Research Centre. 228 p.

Morakotkarn, D., Kawasaki, H., and Seki, T. 2007. Molecular diversity of bamboo associated fungi isolated from Japan. Fems Microbiology Letters 266: 10-19.
Myers, N., Mittermeier, R.A., Mittermeier, C.G., Fonseca, G.A.B., and Kent, J. 2000. Biodiversity hotspots for conservation priorities. Nature. 403: 853-858.

Das, P., and Highland, K. 2010. Arbuscular mycorrhizal fungi and dark septate endophyte colonization in bamboo from Northeast India. Front. Agric. China 2010, 4(3): 375-382 DOI 10.1007/s 11703-010-1013-y.

Paynor, K.A., David, E.S., and Valentino, M.J.G. 2016. Endophytic fungi associated with bamboo as possible sources of single cell protein using corn cob as a substrate. Mycosphere 7(2): 139-147, Doi 10.5943/mycosphere/7/2.

Petrini, O. 1986. Taxonomy of endophytic fungi of aerial plant tissues. In: Fokkema NJ, van den Huevel J, eds. Microbiology of the phyllosphere. Cambridge, UK: Cambridge University Press. 175-187.

Redecker, D., Kodner, R., and Graham, L.E. 2000. Glomalean fungi from the Ordovician. Science 289: 1920-1921.

Saikkonen, K. 2007. Forest structure and fungal endophytes. Fungal Biol Rev 21: $67-74$.

Saikkonen, K., Wäli, P., Helander, M., and Faeth, S.H. 2004. Evolution of endophyte-plant symbioses. Trends Plant Sci 9: 275-280.

Schardl, C.L., Leuchtmann, A., and Spiering, M.J. 2004. Symbioses of grasses with seedborne fungal endophytes. Annu. Rev. Plant Biol. 55: 315-340.

Schardl, C.L., and Phillips, T.D. 1997. Protective grass endophytes: where are they from and where are they going. Plant Disease 81: 430-438.

Shen, X.Y., Cheng, Y.L., Cai, C.J., Fan, L., and Gao, J. 2014. Diversity and Antimicrobial Activity of Culturable Endophytic Fungi Isolated from Moso Bamboo Seeds. PLoS ONE 9(4):e95838. doi:10.1371/journal.pone.0095838. 
Shen, X.Y., Zheng, D.Q., Gao, J., and Hou, C.L. 2012. Isolation and evaluation of endophytic fungi with antimicrobial ability from Phyllostachys edulis. Bangladesh Journal of Pharmacology 7: 249-257.

Shukla, A., Singh, S., and Sehgal, H. 1988. Diseases and deterioration of bamboos in

India. Indian Forester 114: 714-719.

Stone, J.K., Bacon, C.W., and White, J.F. 2000. An overview of endophytic microbes: endophytism defined. Microbial

Strobel, G., Daisy, B., Castillo, U., and Harper, J. 2004. Natural products from endophytic microorganisms. Journal of Natural Products 67: 257-268.

Tanaka, E., Chihiro, T., Abdul, G., and Mitsuya, T. 2002. Heteroepichloë, gen. nov. (Clavicipitaceae; Ascomycotina) on bamboo plants in East Asia. Mycoscience 43: 87-93.

Tanaka, E., Tanaka, C., Ishihara, A., Kuwahara, Y., and Tsuda, M. 2003. Indole-3-acetic acid biosynthesis in Aciculosporium take, a causal agent of witches' broom of bamboo. J Gen Plant Pathol 69: 1-6.

Tanaka, E. 2009. Specific in situ visualization of the pathogenic endophytic fungus Aciculosporium take, the cause of witches' broom in bamboo. Appl Environ Microbiol 75: 4829-34.

Thal, W.M., and Campbell, C.L. 1986. Spatial pattern analysis of disease severity data for alfalfa leaf spot caused primarily by
Leptosphaerulina

briosiana.

Phytopathology 76: 190-194.

Verma, V.C., Kharmar, R.N., and Strobel, G.A. 2009. Chemical and functional diversity of natural products from plant associated endophytic fungi. Natural Product Communications 4: 1511-1532.

Vipin, P., Liza, H., and Priya, D. 2019. Diversity and Distribution of Endomycorrhizae and Dark Septate Endophytes of some Economically Important Bamboos of Assam, India, Not Sci Biol, 11(3): 447-454. DOI: $10.15835 / \mathrm{nsb} 11310343$.

Wan, X., and Chen, Y. 1981. Hypocrellin A, a new drug for photochemotherapy. Kexue Tongbao 26: 1040-1042.

White, J.F.J. 1997. Systematics of the graminicolous clavicipitaceae. In: Bacon, C.W., Nicholas, S.H. (Eds.), Neotyphodium/Grass Interactions. Plenum Press, New York, pp. 27-39.

Wilson, D. 1995. Endophyte; the evolution of a term, and clarification of its use and definition. Oikos. 73: 274-276.

Yang, H.L., Xiao, C.X., Ma, W.X., and He, G.Q. 2009. The production of hypocrellin colorants by submerged cultivation of the medicinal fungus Shiraia bambusicola. Dyes and Pigments 82: 142-146.

Zhan, Z.J., Sun, H.D., Wu, H.M., and Yue J.M. 2003. Chemical components from the fungus Engleromyces goetzei. Acta Botanica Sinica 45: 248-252.

\section{How to cite this article:}

Jentu Giba, Tonlong Wangpan and Sumpam Tangjang. 2020. Endophytic Fungi in Bamboo: A Review. Int.J.Curr.Microbiol.App.Sci. 9(11): 2024-2031. doi: https://doi.org/10.20546/ijcmas.2020.911.241 